\title{
Rapid Automatized Naming (RAN) and Its Relationship to Phonological Awareness and Reading: A Pilot Study in a Greek Sample of Students with Dyslexia
}

\author{
Aglaia Stampoltzis $^{*}$, Eleni Plakida², Eleni Peristeri ${ }^{3}$ \\ ${ }^{1}$ Department of Education, ASPETE, Irini Railway Station, Marousi, Greece \\ ${ }^{2}$ KEMYLO, 45 Agias Paraskevis Street, Athens, Greece \\ ${ }^{3}$ School of Medicine, University of Thessaly, Larissa, Greece \\ Email: ${ }^{\star}$ lstampoltzi@gmail.com
}

How to cite this paper: Stampoltzis, A., Plakida, E., \& Peristeri, E. (2020). Rapid Automatized Naming (RAN) and Its Relationship to Phonological Awareness and Reading: A Pilot Study in a Greek Sample of Students with Dyslexia. Open Journal of Modern Linguistics, 10, 174-194.

https://doi.org/10.4236/ojml.2020.103011

Received: April 25, 2020

Accepted: May 25, 2020

Published: May 28, 2020

Copyright ( 2020 by author(s) and Scientific Research Publishing Inc. This work is licensed under the Creative Commons Attribution International License (CC BY 4.0).

http://creativecommons.org/licenses/by/4.0/

\begin{abstract}
Introduction: Reading impairment in children with dyslexia stems from either a phonological awareness deficit or a deficit in rapid automatized naming. Both deficits constitute the double deficit hypothesis of dyslexia. The aim of the present study was to assess phonological awareness and rapid automatized naming in a group of Greek-speaking children with dyslexia and to correlate their performance in phonological awareness and rapid automatized naming with reading fluency (accuracy and comprehension) scores. Method: Participants were 23 children with a formal diagnosis of dyslexia and 27 typically-developing children with no other learning difficulties or dyslexia. All children were monolingual speakers of Greek and they were administered a naming speed test, a fluency test, a phonological awareness test and reading accuracy and comprehension tasks. Results: Students with dyslexia scored worse in most phonological awareness, rapid automatized naming and reading fluency measures in comparison to their non-dyslexic peers. In addition, students with dyslexia needed more time to complete the rapid automatized naming tests. Positive correlations were found between phonological awareness, rapid automatized naming and reading fluency tests for both groups of students. Specifically, rapid automatized naming and phonological awareness explained $9.3 \%$ and $21.8 \%$, respectively, of the variance in the reading fluency of students with dyslexia, while the respective contributions of rapid automatized naming and phonological awareness to the reading fluency for non-dyslexic students were $2 \%$ and $9.3 \%$, respectively. Discussion and Conclusion: Phonological awareness and rapid automatized naming can be relia-
\end{abstract}


ble predictors of reading fluency even in orthographically consistent languages (i.e., Greek), offering support to the double deficit hypothesis. In addition, combining phonological awareness and rapid automatized naming tests seems to be a quick and reliable way to early identify children at risk of reading difficulties in the first grades of primary school.

\section{Keywords}

Rapid Automatized Naming, Phonological Awareness, Dyslexia, Reading Fluency

\section{Introduction}

There is a significant amount of evidence which suggests that dyslexia is a specific learning disability characterized by poor spelling and decoding abilities, as well as deficient naming speed for highly familiar items. These difficulties typically result from a deficit in phonological and low-level lexical activation processes that are often unexpected in relation to the provision of effective classroom instruction and the dyslexic individual's higher-order cognitive abilities that remain largely preserved (Lyon, Shaywitz, \& Shaywitz, 2003). The present study attempts to study the links between phonological skills, rapid automatized naming and reading efficiency in a Greek sample of students with dyslexia.

More than 40 years have passed since the concept of phonological awareness (PA) appeared into empirical research on the development of reading skills. Phonological awareness is generally defined as the metacognitive ability to reflect upon and manipulate the sounds of spoken words. It is a prerequisite skill of reading development and at the same time an important sub-component of efficient phonological recoding (Bryant et al., 1989; Caravolas, 2005). An important distinction relevant to phonological awareness is that between implicit and explicit phonological processing. Implicit phonological tasks are those in which phonological processing is automatically done, such as verbal short-term memory tasks or rapid automatized naming (RAN). These tasks require access to phonological codes without any explicit reflection on the sound elements of spoken words. On the other hand, explicit phonological tasks, which are usually referred to as PA tasks, require from the child to perceive and manipulate the sounds in words (Melby-Lervag, Lyster, \& Hulme, 2012).

The relationship between PA and literacy acquisition in Greek has recently become the focus of interest by more researchers. Porpodas (1999) was the first to observe that children, who had acquired phonological awareness at a satisfactory level at the pre-reading stage, achieved a better level of literacy development at the end of the first primary year, as compared to their classmates whose level of phonological awareness was low at the prereading stage. Later on, Chitiri \& Porpodas (2003), Tafa (1997) and Papoulia-Tzelepi (1997) have found a strong relationship between phonological awareness and literacy acquisition in Greek. 
Although PA is important as all orthographic systems represent phonological units, it seems to have strong predictive value for the reading speed and orthographic skills in more consistent orthographies, like Greek (Landerl et al., 2019).

Deficits in PA are not the only sources of reading problems. Wolf and Bowers (1999) argued that RAN speed, i.e. the ability to name as fast as possible visually presented, highly familiar symbols, is a second core deficit that may lead to reading disabilities (Papadopoulos, Georgiou, \& Kendeou, 2009). After more than 30 years of research, RAN speed has been found to be strongly related to reading accuracy (e.g. Spring \& Davis, 1988), reading speed (e.g. Berninger et al., 2001; Wimmer, 1993) and reading comprehension (Heikkilä et al., 2009). In addition, the relationship between RAN and reading appears to depend on the type of RAN tasks used (alphanumeric vs. nonalphanumeric) and the type of reading outcomes (reading accuracy vs. reading fluency) that are assessed (Georgiou et al., 2008). Interestingly, Jones, Snowling, and Moll's (2016) RAN-letters study has recently found that the locus of the RAN dimpairment in children with dyslexia does not lie in deficient activation of lexical iformation but is rather due to strong interferece effects from irrelevant-to-target, visually similar items that the children with dyslexia were unale to inhibit. The specific findings suggests that the source of the RAN deficit in dyslexia may be located at the level of higher-order executive function processes, besides lexical activation impairments.

Another imporant element that RAN research has highlighted is the relationship between RAN and reading performance in different developmental stages. According to Bowey, McGuigan \& Ruschena (2005), RAN adds variation to word reading ability from kindergarten to second grade and from first to third grade, but not later on. At the first stages of reading development, both letter knowledge and PA mediate the relationship between RAN and reading performance, whereas at later levels of reading development, it is primarily phonological processing skills that mediate the relationship between RAN and reading. As a result, RAN is important only in the first few years of reading development (Georgiou et al., 2008).

Papadopoulos, Georgiou and Kendeou (2009) have posed the question of whether the coexistence of RAN and PA deficits would result in more severe reading difficulties than single deficits alone. This hypothesis is also known as the 'double deficit hypothesis'. According to relevant research findings, the children that fall under the double deficit group experience the most severe reading difficulties, followed by the children that fall under the single-deficit (either the PA or the RAN deficit) groups (Wolf \& Bowers, 1999; Wolf et al., 2002). In the same line, Gharaibeh and colleagues (2019) have examined the reading performance of three groups of children, one with a PA deficit, one with a RAN deficit and one with double deficit. According to their results, the lowest levels of reading were observed for the double deficit group followed by the PA and, finally, the RAN-deficit group. The same pattern of performance has been replicated by Yang and Pae's (2018) study in Korean-speaking children with dyslexia. 
There are limited studies of the effects of RAN and PA on reading achievement in Greek. A Greek longitudinal study that has investigated the double deficit hypothesis is one by Papadopoulos, Georgiou and Kendeou (2009). Experimental participants were split into four groups on the basis of two composite scores of phonological and naming-speed criterion measures: a double deficit group (DD), a phonological deficit group (PD), a naming deficit group (ND), and a control group with no deficits $(\mathrm{CnD})$. The results showed that the $\mathrm{DD}$ group exhibited lower performance in reading and orthographic processing compared to the single deficit (PD or $\mathrm{ND}$ ) and $\mathrm{CnD}$ groups. Crucially, between-group differences were the most striking in grades 1 and 2. This study offered evidence that the double deficit hypothesis also applies to the Greek language although the latter is much more transparent than English in the representation of phonology. Also, the particular longitudinal study showed that the children falling under the double deficit hypothesis faced the most persistent reading difficulties at developmental stages.

Another aspect of the double déficit hypothesis concerns the interaction between RAN and PA and the strength of their inter-relation developmentally. There is evidence that the moderate positive correlation between the two skills decreases over time (Swanson et al., 2003; Wolf et al., 2002; Wagner, Torgesen, \& Rashotte, 1999), which suggests that both skills contribute individually to reading variance (Manis, Seidenberg, \& Doi, 1999). Interestingly, it has been found that, even after the effects of PA have been controlled, RAN continues to contribute significantly to the variance in reading accuracy (Lervåg, Bråten, \& Hulme, 2009; McBride-Chang \& Manis, 1996). These findings support the idea of RAN as a separate subcomponent of one's reading abilities.

A critical factor regarding the validity of the double deficit hypothesis is the way it is affected by the transparency of the testing language. Whereas English has an opaque orthography with no consistent grapheme to phoneme correspendences, German, Dutch, Italian and Spanish are relatively more transparent languages with more consistent grapho-phonemic mappings. Vaessen and colleagues (2010) found that phonological awareness contributed to reading fluency to a greater extent in languages with opaque orthographies than in laguages with transparent orthographies for readers attending grades 1 to 4 . However, RAN contributed to a similar degree to reading fluency regardless of the language's transparency (see also Ziegler et al., 2011). In addition, Moll et al. (2009) found that for typical fourth-grade readers of German, RAN contributed more significantly to reading fluency when compared to PA.

Another point which deserves attention is the type of RAN tasks (alphanumeric and non-alphanumeric) that better correlates with reading accuracy skills. It has been reported that RAN alphanumeric (i.e. letters and digits) tasks as a combined measure may better predict word recognition, reading accuracy and speed as well as reading comprehension than non-alphanumeric (i.e. colours and objects) tasks (Davis et al., 2001; Misra et al., 2004). However, Meyer et al. (1998) 
suggest that RAN non-alphanumeric tasks predict reading fluency and vocabulary more effectively than than RAN letter and digit tasks across all grades.

The enhanced sensitivity of RAN measures to reading has been largely attributed to the degree of stimulus automatization. Researchers that argue that RAN letter and digit tasks have a strong predictive vaule for reading skills claim that as chidren grow up they are not sufficiently exposed to colors and object naming tasks and, as such, they are more familiar with alphanumeric (vs non-alphanumeric) tasks (Meyer et al., 1998; Misra et al., 2004). On the other hand, researchers who consider non-alphaneumeric RAN measures to be better predictive indices of an individual's reading abilities argue that non-alpaneumeric tap into general processing speed which is not affected by familiarity with symbols (Van den Bos, Zijlstra, \& Spelberg, 2002; Waber et al., 2000).

Stanovich (1988) and Fawcett \& Nicolson (1994) claim that there is solid evidence of a deficit in the early phonological skills of children with dyslexia which is accompanied by abnormally slowed speed of auditory processing and an impairment in the ability to detect visual flickers (Lovegrove, Garzia, \& Nicholson, 1990). One of the most important aspects of the RAN tasks is their sensitivity to dyslexia, since RAN has been found to differentiate children with dyslexia both from groups with diverse learning disabilities, other-than-dyslexia and from typically-developing controls (Fawcett \& Nicolson, 1994). As Waber et al. (2000) mention, different diagnostic groups may demonstrate naming speed deficits for different reasons. For several researchers (e.g. Brizzolara et al., 2006; Misra et al., 2004; Savage et al., 2007; Wimmer \& Mayringer, 2002), deficits in RAN are the best predictive markers for dyslexia-related difficulties in children and adults. Crucially, the same studies point out that RAN tasks have a strong long-term predictive value for dyslexia diagnosis in languages with transparent orthographic systems.

Fawcett and Nicolson (1994) have investigated children's naming speed in tasks with stimuli of diverse forms. Seven groups of children, comprising three groups of children with dyslexia, three groups of normally-achieving children matched for age and IQ with the dyslexic groups, and a group of 10-year-old children with mild learning difficulties (slow learners) took part in the study. According to the results, children with dyslexia exhibited persistent, and unexpectedly severe naming speed deficits across all stimuli conditions, regardless of whether the stimulus required grapheme-phoneme decoding. The authors concluded that children with dyslexia may have impaired speed of access to their lexicon for all types of stimuli, irrespective of the mode of stimulus presentation (Fawcett \& Nicolson, 1994: p. 9). The inter-relationship between RAN, PA and reading in different languages and grade levels seems to be promising for the development of tools targeting the early identification of dyslexia and reading difficulties.

\section{Objectives and Hypotheses}

The aim of the present study was to examine the relationship between RAN, PA 
and reading in a sample of Greek students with a diagnosis of dyslexia and an age- and IQ-matched control group. The current study sets the following research questions and hypotheses:

Question 1. Will there be any differences between dyslexic and non-dyslexic children in RAN and PA measures?

Hypothesis 1. We hypothesized that dyslexic students in our study would perform significantly lower than controls in both RAN and PA measures, in line with a number of studies reporting RAN and PA deficits driven by dyslexia (Porpodas, 1999; Chitiri \& Porpodas, 2003; Tafa, 1997; Papoulia-Tzelepi, 1997).

Question 2. Will students with dyslexia differ from their matched controls in reading fluency measures?

Hypothesis 2. Based on previous evidence (Porpodas, 1999; Chitiri \& Porpodas, 2003; Tafa, 1997) that reading dysfluency is one of the major disabling features of dyslexia, we hypothesized that the children with dyslexia in the current study would exhibit lower performance than their matched controls in reading fluency measures.

Question 3. Which RAN measure(s) correlate(s) best with PA and reading measures in dyslexic and non-dyslexic students?

Hypothesis 3. Based on the majority of previous studies (e.g. Davis et al., 2001; Gharaibeh et al., 2019; Jones et al., 2016; Misra et al., 2004) claiming that RAN digit tasks are more powerful predictors of dyslexic children's reading performance relative to object naming tasks, we hypothesized that digit-naming measures in the current study would explain a larger amount of variance in children's reading performance than pictured object naming.

Question 4. What is the contribution of RAN and PA in the reading fluency of each group?

Hypothesis 4. Though the evidence on the joint contribution of the RAN and PA deficits in dyslexia is limited and hints at the fact that RAN deficits load more on dyslexic children's reading fluency compared to PA deficits (Gharaibeh et al., 2019; Papadopoulos et al., 2009; Yang \& Pae, 2018), we hypothesized that deficits in RAN would account for higher amounts of variance of the children's reading performance than the PA deficit.

\section{Method}

\subsection{Participants}

Fifty Greek-speaking children (26 boys and 24 girls; mean age: 8 yrs.; grades: 2nd to $4^{\text {th }}$ ) took part in the study. Children were recruited from two areas of the city of Athens and they all had an average socioeconomic status. Twenty-three children ( 15 boys and 8 girls) had a formal diagnosis of dyslexia or reading difficulties, and twenty-seven ( 9 boys and 18 girls) had no learning, behavioural or sensory difficulties. Children from both groups (dyslexic and control) were matched for grade, age and general cogntitive ability/IQ. The later was measured by the Raven Colored Progressive Matrices (RCPM). Raven scores were within 
normal range for both groups. No significant differences in the RCPM were found between students with dyslexia and controls $(p=0.05)$.

\subsection{Measures}

\section{Naming speed tests (picture and digit)}

Picture and digit naming tests are part of the Phonological Assessment Battery (Frederickson, Frith \& Reason, 1997). They assess a child's speed of phonological production. More specifically, they evaluate a child's response to visual stimuli presented in random order from left to right. The time that the child needs to complete the tests is calculated along with the errors made. These two tasks are non-verbal, thus, they can be administered to non-English speaking children.

\section{Fluency Test}

The Fluency Test which is part of the Phonological Assessment Battery (Frederickson, Frith, \& Reason, 1997), evaluates a child's ability to recall phonological and semantic representations from long-term memory and to name them quickly within a time limit of 30 seconds. The Fluency Test consists of three subtests (semantic, alliteration and rhyme). A total score was calculated based on the number of the words recalled during the time limit in each sub-test.

\section{The Stroop Color and Word Test}

The Stroop Color and Word Test (SCWT) assesses one's ability to inhibit interference, (Stroop, 1935). In this task, subjects were required to read three different tables as fast as possible. In two of them, children were required to read names of colors (color-words) printed in black ink and name different color patches. Conversely, in the third table, named as the color-word (CW) condition, color-words were printed in an inconsistent color ink (for instance the word "red" was printed in green ink). Thus, in the incongruent condition, participants were required to name the color of the ink instead of reading the word (Scarpina \& Tagini, 2017). Errors and speed of performance were calculated for each child in each table and a total Stroop time and Stroop performance score was obtained. While the SCWT is primarily used to measure the ability to inhibit interference (the Stroop effect), in the present study it has been used as a measure of processing speed and working memory (Jensen, 1965; Kane \& Engle, 2003).

\section{A Greek Informal Battery of Phonological Awareness}

A non-standardised Test of Phonological Awareness was designed by the researchers of the current study to assess four aspects of phonological processing: sentence awareness, syllabic awareness (analysis and synthesis), phonemic awareness (analysis and synthesis) and rhyme awareness (recognition and production). Examples were given for each task before testing. Correct answers were scored with 1 while wrong answers with 0 . The sentence awareness had a score of $0-7$, the syllabic awareness a score of $0-28$, the phonemic awareness a score of 0 - 28 and the rhyme awareness a score of $0-14$. A total PA score was calculated per child by adding the subscores. 
The Greek Test of Reading Fluency (Zeliou, Sini, Anagnostopoulou, \& Lazaratou, 2008).

The Greek Test for Reading Fluency consists of one text which is based on a Greek myth. The text is accompanied by nine questions that assess reading comprehension. It is standardised for 7-to-8 year old Greek-speaking children with high reliability and validity scores for reading time, reading errors and comprehension (Zeliou et al., 2008). The child was asked to read aloud the text and his/her reading was tape-recorded so that his/her errors could be analysed through miscue analysis. The total reading time the child needed to read the text from the first to the last word was recorded. The child's oral answers to the nine comprehension questions were also evaluated and counted. A composite score of reading fluency based on the child's reading accuracy, speed and reading comprehension was calculated (see the Appendix).

According to the reliability analysis, Cronbach a $=0.713$ was obtained for the 33 items (variables) of the study. The individual Cronbach a value for each test were: Naming Speed $\mathrm{a}=0.604$, Fluency Test $\mathrm{a}=0.751$, Stroop Test $\mathrm{a}=0.520$, Phonological Awareness $\mathrm{a}=0.542$, reading $\mathrm{a}=0.887$. Because of the small sized experimental sample, it was difficult to obtain a higher reliability index for each of the sub-tests. In addition, the tests that have been administered in the present study were piloted with three children so as to make sure that the instructions and the tasks would be understandable by children of all ages.

\subsection{Procedure}

Both groups of children completed the following tasks in a fixed order: 1) picture and digit naming tests, 2) the reading fluency test, 3) the Stroop color and word test, 4) the phonological awareness test battery, and, finally, 5) the Greek test of reading fluency. Written permission from the parents was obtained prior to testing. Children were tested individually in a quiet room by the second author during school hours. Participants completed the tasks in three different testing sessions (the first included the picture and digit naming tests $\left(1^{\text {st }}\right.$ session duration: 20 minutes approximately), the second included the reading fluency test and the Stroop color and word test $\left(2^{\text {nd }}\right.$ session duration: 30 minutes approximately), and the third session included the phonological awareness test battery and the Greek test of reading fluency ( $3^{\text {rd }}$ session duration: 40 minutes approximately), separated by a minimum duration of 1 week. Data collection took place over a period of two months (October-November 2019). All tests were scored separately by the first and second authors following the guidelines of each test. Scores per test were the compared, with the comparison reaching $98 \%$ agreement.

\subsection{Data Analysis}

Statistical analysis was carried out with SPSS version 19. A preliminary analysis was made to test the normality of the variables through the Shapiro-Wilk test $(\mathrm{N}$ 
$<50$ ). The variables did not have a normal distribution, therefore, non-parametric statistics were used to compare the scores of dyslexic and control children. Descriptive and inferential statistics were used to analyze the data and regression models were used to investigate the extent to which RAN and PA predicted the groups' reading fluency (accuracy and comprehension).

\section{Results}

Table 1 presents the descriptive statistics for the RAN measures used in the study.

The next Table 2 presents the descriptive statistics for the RAN measures.

In the next section (Table 3) we see the descriptive statistics for the PA (sub-categories and total score) as well as the reading fluency measures.

To compare the scores of students with dyslexia and the control group, a Mann-Whitney test was performed. The between-group comparisons for the RAN measures are presented in Table 4.

Table 1. Means (and SD) of dyslexic and control groups' accuracy performance in the naming, fluency and Stroop measures.

\begin{tabular}{|c|c|c|c|c|c|}
\hline Variables & Groups (N) & Mean & $\mathrm{SD}$ & $\operatorname{Min}$ & $\operatorname{Max}$ \\
\hline \multirow[t]{2}{*}{ Naming Objects Card 1} & Dyslexic (23) & 48.2 & 2.5 & 41 & 50 \\
\hline & Control (27) & 49.6 & 0.7 & 47 & 50 \\
\hline \multirow[t]{2}{*}{ Naming Objects Card 2} & Dyslexic & 47.9 & 3.2 & 35 & 50 \\
\hline & Control & 49.5 & 1.0 & 47 & 50 \\
\hline \multirow[t]{2}{*}{ Digit Naming Card 1} & Dyslexic & 48.9 & 1.6 & 43 & 50 \\
\hline & Control & 49.7 & 0.6 & 48 & 50 \\
\hline \multirow[t]{2}{*}{ Digit Naming Card 2} & Dyslexic & 48.9 & 2.2 & 42 & 50 \\
\hline & Control & 49.9 & 0.2 & 49 & 50 \\
\hline \multirow[t]{2}{*}{ Naming Objects and Digits Total Score } & Dyslexic & 194.1 & 6.5 & 174 & 200 \\
\hline & Control & 198.7 & 1.5 & 194 & 200 \\
\hline \multirow[t]{2}{*}{ Fluency Semantic } & Dyslexic & 13.00 & 2.8 & 8 & 20 \\
\hline & Control & 19.2 & 3.7 & 12 & 27 \\
\hline \multirow[t]{2}{*}{ Fluency Alliteration } & Dyslexic & 9.4 & 3.6 & 4 & 18 \\
\hline & Control & 12.00 & 4.2 & 7 & 23 \\
\hline \multirow[t]{2}{*}{ Fluency Rhyme } & Dyslexic & 5.5 & 3.4 & 1 & 14 \\
\hline & Control & 10.8 & 3.9 & 4 & 18 \\
\hline \multirow[t]{2}{*}{ Total Fluency Score (Ph.AB) } & Dyslexic & 27.8 & 7.3 & 15 & 48 \\
\hline & Control & 40.2 & 11.8 & 9 & 60 \\
\hline \multirow[t]{2}{*}{ Stroop 1 Reading B + W words } & Dyslexic & 11.4 & 0.7 & 9 & 12 \\
\hline & Control & 11.5 & 0.5 & 11 & 12 \\
\hline \multirow[t]{2}{*}{ Stroop 2 Reading Colored words } & Dyslexic & 11.7 & 0.6 & 10 & 12 \\
\hline & Control & 12.00 & 0.0 & 12 & 12 \\
\hline \multirow[t]{2}{*}{ Stroop 3 Naming Word Color } & Dyslexic & 11.2 & 0.9 & 9 & 12 \\
\hline & Control & 11.5 & 0.7 & 10 & 12 \\
\hline \multirow[t]{2}{*}{ Stroop Total score } & Dyslexic & 34.3 & 1.6 & 30 & 36 \\
\hline & Control & 35.1 & 0.9 & 33 & 36 \\
\hline
\end{tabular}


Table 2. Means (and SD) of dyslexic and control groups' timing performace in the naming, fluency and Stroop measures.

\begin{tabular}{|c|c|c|c|c|c|}
\hline Variables & Groups (N) & Mean & SD & Min & Max \\
\hline \multirow[t]{2}{*}{ Naming Objects Card 1 time (sec) } & Dyslexic (23) & 71.3 & 20.3 & 48 & 116 \\
\hline & Control (27) & 47.8 & 9.5 & 47 & 50 \\
\hline \multirow[t]{2}{*}{ Naming Objects Card 2 time (sec) } & Control & 68.7 & 21.8 & 12 & 117 \\
\hline & Dyslexic & 47.6 & 10.7 & 26 & 68 \\
\hline \multirow[t]{2}{*}{ Naming Objects average time (sec) } & Dyslexic & 72.3 & 20.3 & 46 & 118 \\
\hline & Control & 47.1 & 11.1 & 26 & 68 \\
\hline \multirow[t]{2}{*}{ Digit Naming Card 1 time (sec) } & Dyslexic & 39.3 & 13.1 & 21 & 69 \\
\hline & Control & 32.7 & 9.7 & 20 & 52 \\
\hline \multirow[t]{2}{*}{ Digit Naming Card 2 time (sec) } & Dyslexic & 40.0 & 14.5 & 22 & 80 \\
\hline & Control & 32.7 & 9.9 & 21 & 52 \\
\hline \multirow[t]{2}{*}{ Digit Naming Average time (sec) } & Dyslexic & 39.9 & 13.3 & 25 & 75 \\
\hline & Control & 32.7 & 9.7 & 21 & 52 \\
\hline \multirow[t]{2}{*}{ Naming (Objects and Digits) average time (sec) } & Dyslexic & 56.7 & 14.3 & 37 & 87 \\
\hline & Control & 39.8 & 9.8 & 24 & 57 \\
\hline \multirow[t]{2}{*}{ Stroop 1 Reading B + W words time } & Dyslexic & 15.0 & 6.9 & 6 & 32 \\
\hline & Control & 8.5 & 2.7 & 4 & 15 \\
\hline \multirow[t]{2}{*}{ Stroop 2 Reading Colored words time (sec) } & Dyslexic & 14.2 & 7.3 & 5 & 34 \\
\hline & Control & 9.0 & 3.1 & 4 & 16 \\
\hline \multirow[t]{2}{*}{ Stroop 3 Naming Word Color time (sec) } & Dyslexic & 29.2 & 13.7 & 12 & 70 \\
\hline & Control & 20.1 & 5.1 & 13 & 34 \\
\hline \multirow[t]{2}{*}{ Stroop Total time score (sec) } & Dyslexic & 58.6 & 22.6 & 23 & 112 \\
\hline & Control & 37.3 & 8.1 & 25 & 51 \\
\hline
\end{tabular}

Table 3. Means (and SD) of dyslexic and control groups' performance in the PA and reading measures.

\begin{tabular}{cccccc}
\hline Variables & Groups (N) & Mean & S.D & Min & Max \\
\hline Phonological Awareness Sentence & Dyslexic (23) & 3.1 & 1.2 & 0 & 5 \\
& Control (27) & 5.1 & 1.3 & 3 & 7 \\
Phonological Awareness Syllables & Dyslexic & 26.5 & 1.6 & 22 & 28 \\
& Control & 27.3 & 2.7 & 14 & 28 \\
Phonological Awareness Phonemes & Dyslexic & 17.1 & 5.4 & 8 & 26 \\
& Control & 21.2 & 4.1 & 12 & 28 \\
Phonological Awareness Rhyme & Dyslexic & 8.9 & 2.5 & 3 & 13 \\
Phonological Awareness Total & Control & 12.0 & 1.3 & 9 & 14 \\
Reading accuracy score & Dyslexic & 55.3 & 7.6 & 42 & 72 \\
& Control & 65.6 & 6.1 & 56 & 76 \\
Reading comprehension & Dyslexic & 2.3 & 0.7 & 1 & 3 \\
& Control & 4.2 & 0.8 & 2 & 5
\end{tabular}


Table 4. Results of the Mann-Whitney test in the RAN measures.

\begin{tabular}{|c|c|c|c|}
\hline Variables & Mann-Whitney $U$ & $Z$ & $\begin{array}{c}\text { Sigificance } \\
(2 \text {-tailed })\end{array}$ \\
\hline Naming Objects Card 1 Score & 222.000 & -1.979 & $0.048^{*}$ \\
\hline Naming Objects Card 2 Score & 170.500 & -3.046 & $0.002^{\star *}$ \\
\hline Digit Naming Card 1 Score & 219.000 & -2.120 & $0.034^{*}$ \\
\hline Digit Naming Card 2 Score & 212.000 & -2.865 & $0.004^{* *}$ \\
\hline Naming Objects and Digits Total Score & 141.000 & -3.374 & $0.001^{* *}$ \\
\hline Fluency Test Semantic Score & 53.000 & -5.027 & $0.000^{\star * *}$ \\
\hline Fluency Test Allieration Score & 202.500 & -2.113 & $0.035^{*}$ \\
\hline Fluency Test Rhyme Score & 100.000 & -4.109 & $0.000^{\star * *}$ \\
\hline PhaB Fluency Test Total Score & 102.500 & -4.052 & $0.000^{* * *}$ \\
\hline Stroop 1 Reading B+W Words Score & 307.500 & -.067 & 0.946 \\
\hline Stroop 2 Reading Colored Words Score & 256.500 & -2.235 & $0.025^{*}$ \\
\hline Stroop 3 Naming Words Color Score & 244.500 & -1.465 & 0.143 \\
\hline Stroop Total Score & 228.000 & -1.679 & 0.093 \\
\hline Naming Objects Card 1 Time (sec) & 70.500 & -4.674 & $0.000^{\star * \star}$ \\
\hline Naming Objects Card 2 Time (sec) & 96.500 & -4.168 & $0.000^{\star * \star}$ \\
\hline Naming Objects Average Time (sec) & 74.500 & -4.598 & $0.000^{\star * *}$ \\
\hline Digit Naming Card 1 Time (sec) & 211.500 & -1.929 & 0.054 \\
\hline Digit Naming Card 2 Time (sec) & 215.500 & -1.852 & 0.064 \\
\hline Digit Naming Average Time (sec) & 202.500 & -2.105 & $0.035^{*}$ \\
\hline Naming Obj-Dig. Average Time (sec) & 104.000 & -4.024 & $0.000^{* * *}$ \\
\hline Stroop 1 Reading B + W Words Time & 95.500 & -4.205 & $0.000^{* * *}$ \\
\hline Stroop 2 Reading CW Time (sec) & 146.000 & -3.216 & $0.001^{\star * *}$ \\
\hline Stroop 3 Naming Words Color Time (sec) & 175.000 & -2.642 & $0.008^{* *}$ \\
\hline Stroop Total Time (sec) & 104.000 & -4.022 & $0.000^{\star \star \star *}$ \\
\hline
\end{tabular}

${ }^{\star} p<0.05,{ }^{* *} p<0.01,{ }^{* * *} p<0.001$.

The results of the Mann-Whitney test for the PA and reading tasks are presented in Table 5.

Pearson's bivariate correlations were conducted among the RAN, PA and reading measures to investigate their interrelationship. The output of the correlations is summarized in Table 6.

Linear regression analyses were subsequently performed to examine the effect of RAN and PA on reading separately for the dyslexic and the control group. The results for the dyslexic and the control group are presented in Table 7 and Table 8, respectively.

To summarize, RAN and PA were found to explain $2.0 \%$ and $9.3 \%$, respectively, of the variance in reading fluency for the control group. On the other 
hand, RAN and PA were found to explain $9.3 \%$ and $21.8 \%$, respectively, of the variance in reading fluency for the group with dyslexia.

Table 5. Results of the Mann-Whitney test for the PA and reading measures.

\begin{tabular}{cccc}
\hline Variables & Mann-Whitney $U$ & $Z$ & $\begin{array}{c}\text { Significance } \\
\text { (2-tailed) }\end{array}$ \\
\hline Phonological Awareness A: Sentences & 90.500 & -4.369 & $0.000^{* * *}$ \\
Phonological Awareness B: Syllables & 153.000 & -3.579 & $0.000^{* * *}$ \\
Phonological Awareness C: Phoneme & 173.000 & -2.685 & $0.007^{* *}$ \\
Phonological Awareness D: Rhyme & 82.000 & -4.492 & $0.000^{* * *}$ \\
Phonological Awareness Total & 89.000 & -4.331 & $0.000^{* * *}$ \\
Reading Accuracy score & 46.000 & -5.329 & $0.000^{* * *}$ \\
Reading Comprehension & 105.000 & -4.233 & $0.000^{* * *}$ \\
Reading Time & 40.000 & -5.413 & $0.000^{* * *}$ \\
Reading Fluency (composite score) & 16.000 & -5.799 & $0.000^{* * *}$
\end{tabular}

Table 6. Correlations between the RAN, PA and reading measures.

\begin{tabular}{cccccc}
\hline & NOBD total & Fluency total & Stroop total & NO + ND time & Stroop time \\
\hline PA total & & $0.404^{* *}$ & $0.398^{* *}$ & $-0.436^{* *}$ & $-0.545^{* *}$ \\
& & 0.004 & 0.004 & 0.000 & 0.000 \\
Read.acc. & $0.516^{* *}$ & $0.599^{* *}$ & $0.361^{*}$ & $-0.706^{* *}$ & $-0.622^{* *}$ \\
& 0.000 & 0.000 & 0.010 & 0.000 & 0.000 \\
Read.compr. & $0.313^{*}$ & $0.624^{* *}$ & & $-0.515^{* *}$ & $-0.471^{* *}$ \\
& 0.027 & 0.000 & & 0.000 & 0.001 \\
Read.time & $0.404^{* *}$ & $0.668^{* *}$ & & $-0.675^{* *}$ & $-0.540^{* *}$ \\
& $0.004^{* *}$ & 0.000 & & 0.000 & 0.000 \\
Reading & $0.479^{* *}$ & $0.687^{* *}$ & $0.331^{*}$ & $-0.740^{* *}$ & $-0.626^{* *}$ \\
fluency & 0.000 & 0.000 & 0.019 & 0.000 & 0.000 \\
\hline
\end{tabular}

${ }^{*}$ Correlation is significant at the 0.05 level (2-tailed); ${ }^{* *}$ Correlation is significant at the 0.01 level (2-tailed); Note: NOBD total: Naming Objects and Digits total score, NO + ND time: Naming Objects and Digit time, PA total: Phonological Awareness Total, Read. acc: Reading accuracy score, Read.compr: Reading Comprehension Score, Read.time: Reading time.

Table 7. Regression analysis for the dyslexic group

\begin{tabular}{ccccc}
\hline \multicolumn{5}{c}{ Model Summary } \\
\hline Model & R & R Square & Adjusted R Square & Std. Error of the Estimate \\
\hline 1 & $0.305^{\mathrm{a}}$ & 0.133 & 0.093 & 1.163 \\
\hline \multicolumn{5}{c}{ Model Summary } \\
\hline 1 & R & R Square & Adjusted R Square & Std. Error of the Estimate \\
\hline & $0.467^{\mathrm{b}}$ & 0.255 & 0.218 & 1.079 \\
\hline
\end{tabular}

a. Predictors: (Constant), Naming Objects and Digits Total Score (RAN); b. Predictors: (Constant), Phonological Awareness Total. 
Table 8. Regression analysis for the control group

\begin{tabular}{ccccc}
\hline \multicolumn{5}{c}{ Model Summary } \\
\hline Model & R & R Square & Adjusted R Square & Std. Error of the Estimate \\
\hline 1 & $0.142^{\mathrm{a}}$ & 0.021 & 0.020 & 1.639 \\
\hline \multicolumn{5}{c}{ Model Summary } \\
\hline Model & $\mathrm{R}$ & R Square & Adjusted R Square & Std. Error of the Estimate \\
\hline 1 & $0.304^{\mathrm{b}}$ & 0.130 & 0.093 & 1.577 \\
\hline
\end{tabular}

a. Predictors: (Constant), Naming Objects and Digits Total Score (RAN); b. Predictors: (Constant), Phonological Awareness Total

\section{Discussion}

The aim of the present study was to examine the performance of Greek students with dyslexia and controls in different RAN, PA and reading measures. Overall, the study found that students with dyslexia performed significantly worse than matched controls in the tasks tapping into PA and RAN, and, crucially, that PA, rather than RAN, was the strongest predictor of both dyslexic and control groups' reading accuracy and comprehension performance.

The first aim of the study was to investigate whether the students with dyslexia would exhibit any PA or/and RAN deficits. Our finding replicated previous research in that the students with dyslexia scored worse in the Naming Speed (object and digits) and the fluency test in comparison to their non-dyslexic peers. In addition, students with dyslexia took longer than normal readers to complete all RAN tests, which suggests that they had slower speed of processing when they were presented with naming tasks in general. Similar findings have been reported by Fawcett and Nicolson (1994), although the source of slow naming ability may be attributed to general cognitive skills (Heikkilä et al., 2009). Denckla and Rudel (1976) noted that timing performance in RAN was related to how "automatized" the naming process was. According to Wolf and Bowers (1999), RAN (especially letter and digit tests) draws on a variety of cognitive, attentional and linguistic resources. Slow RAN performance may, thus, reflect a breakdown within a specific sub-process or a failure to integrate information from all relevant sources (Wolf \& Bowers, 1999). The timing dimension of the RAN tasks seems to be an important factor to examine in with dyslexic students and controls. The analyses also yielded high statistically significant differences between dyslexic students and controls in all PA measures.

What should be noted, however, is that, while dyslexic students showed longer response times than typically-developing children, there were no significant between-group differences in the raw accuracy measure of the Stroop test. This finding implies that the children with dyslexia that participated in the current study had no inhibition deficit and managed to effectively suppress interfering no-relevant-to-task stimuli along with their matched controls. This pattern comes into contrast with Jones et al.'s (2016) study that found that children with 
dyslexia had persistent difficulty inhibiting interfering stimuli in a Stroop-switch task. We hypothesize that the difference between Jones et al.'s (2016) and our study stems from the different ages of participant groups, since students in the current study attended primary school, while students in Jones et al.'s (2016) study attended tertiary education. The fact that university students with dyslexia exhibited an inhibition deficit as evinced by the stroop task, while our students did not exhibit, implies that inhibitory skills in dyslexia may worsen with age. In general, Stroop tests tap into a variety of executive functions including processing efficiency, inhibition and cognitive flexibility (Scarpina \& Tagini, 2017). They require rapid processing of text and increased speed and accuracy of reading, but according to Logan (1997) automaticity is probably not a unitary construct when it applies to reading development. Since no single component can be identified as being responsible for the dyslexic students' control-like accuracy performance in the Stroop task of the current study, our assumptions should be treated with caution and be replicated by longitudinal study designs.

The second research question of our study concerns the students' performance in the reading tasks. The analyses yielded highly statistically significant differences between dyslexic students and controls in all reading measures. Reading time as a variable of reading fluency has been found to give raise to significant differences between dyslexic and control groups in a number of studies (e.g. Diamanti et al. 2018; Fischer \& Weber, 1990; Nicolson \& Fawcett, 1994) which implies that timing measures (besides offline tests) should be taken into account when researchers and teachers test children's reading fluency.

The third question of the study sheds light into the type of RAN measure(s) that correlated best with PA and reading measures in dyslexic and non-dyslexic students. RAN object and digit subtests were found to have a similar effect on the children' reading skills, in spite of the fact that the RAN object test is a non-alphanumeric measure and RAN digit is an alphanumeric measure. This pattern of performance may be attributed to the fact that the students of our sample were exposed to the same degree to both types of stimuli. According to Misra et al. (2004), RAN objects and color measures are reliable predictive indicators of reading skills only for students attending the first grades, while RAN letter and number measures retain their predictive value for typical readers' reading performance for many years until adulthood. Furthermore, the correlations found between the experimental variables offer an interesting picture of the interrelationship between PA, RAN and reading. Naming (Objects and Digits) (representing RAN) had a medium but significant positive correlation with all reading measures, thus, hinting at its role as an underlying mechanism of reading processes. It also had a weaker, though significant positive correlation with the Stroop accuracy score and a medium negative correlation with the timing variables of the Naming Object, Digit Naming, and Stroop tasks. Also, the fluency variable had a medium to high significant correlation with PA and all reading measures, and a negative medium to high correlation with the timing 
variables of the Naming Object, Digit Naming, and Stroop tasks. The Stroop time correlated negatively with PA and the reading measures, which is in line with Protopapas, Archonti and Skaloumbakas's (2007) finding that greater Stroop interference was linked to lower reading skills for dyslexic students attending the 7th grade sample. The correlations holding between PA and reading measures (accuracy, time and comprehension) were found to be high in our study. This is in line with previous research in languages with an alphabetic script (Porpodas, 1999; Snowling, 2000; Brizzolara et al., 2006; Papadopoulos et al., 2009) that offer converging evidence for PA's high predictive value of early reading performance in terms of both reading accuracy and comprehension. Our findings particularly corroborate the assumption that children experiencing phonological difficulties at first grade are at risk of developing reading difficulties later on in their lives (Bradley \& Bryant, 1983).

The final research question of the current study relates to RAN's and PA's potentially distinct contributions to the reading fluency of each experimental group. According to our results, the contributions of RAN and PA have been found to be stronger for the dyslexic group than the controls. This finding is in line with the literature underlying the predictive value of RAN and PA tests in diagnosing dyslexia and related learning difficulties even in grapho-phonemically transparent languages (Brizzolara et al., 2006; Misra et al., 2004; Savage et al., 2007; Papadopoulos, Georgiou, \& Kendeou, 2009). The present study adds to the ongoing discussion about the deficits in RAN and PA in Greek-speaking children with dyslexia and highlights the need to to further explore the double deficit hypothesis. The predictive value of the RAN measures was found to be stronger for the dyslexic children in the current study, which highlights the role of the specific cognitive skill in predicting reading achievement in the specific population.

Characterization of reading deficits in dyslexia through the lens of PA and, especially, RAN impairments may have important implications for both understanding the cognitive domains or skills that are vulnerable to delay in dyslexia and designing potentially targeted interventions. Specifically, deficits in PA and RAN should be detected as soon as possible to prevent reading failure and related learning difficulties (Fawcett \& Nicolson, 1994; Brizzolara et al., 2006). Specialists may also take advantage of PA and RAN measures to early detect the skills that need to be trained in the children before they receive reading instruction. Furthermore, children with dyslexia may benefit from interventions focusing primarily on the enhancement of phonological awareness and confrontation naming which may lead to growth in their reading skills.

There are specific limitations to this study. First, the results cannot be generalised because of the small sample that prevented us from investigating a wider age range. Second, we didn't use standardized measures in Greek for all the testing variables, and as such we should be cautious while interpreting the findings. Third, the size of the sample did not allow a more sophisticated statistical analy- 
sis (e.g. structural equation model) design to study in depth the extent to which reading is mediated by PA and RAN.

\section{Conclusion}

To sum up, the overall findings have practical implications in that they highlight the utility of PA and RAN measures in dyslexia assessment, and more specifically, in the evaluation of dyslexic children' cognitive and naming abilities. The findings stress the need to design and implement intervention programs and remedial teaching activities to train students in PA and RAN skills in order to improve their reading performance.

\section{Conflicts of Interest}

The authors declare no conflicts of interest regarding the publication of this paper.

\section{References}

Berninger, V. W., Abbott, R. D., Thomson, J. B., \& Raskind, W. H. (2001). Language Phenotype for Reading and Writing Disability: A Family Approach. Scientific Studies of Reading, 5, 59-106. https://psycnet.apa.org/doi/10.1207/S1532799xssr0501 3 https://doi.org/10.1207/S1532799XSSR0501 3

Bowey, J. A., McGuigan, M., \& Ruschena, A. (2005). On the Association between Serial Naming Speed for Letters and Digits and Word-Reading Skill: Towards a Developmental Account. Journal of Research in Reading, 28, 400-422. https://psycnet.apa.org/doi/10.1111/j.1467-9817.2005.00278.x https://doi.org/10.1111/j.1467-9817.2005.00278.x

Bradley, L., \& Bryant, P. E. (1983). Categorizing Sounds and Learning to Read-A Causal Connection. Nature, 301, 419-421. https://doi.org/10.1038/301419a0

Brizzolara, D., Chilosi, A., Cipriani, P., Di Filippo, G., Gasperini, F., Mazzotti, S., \& Zoccolotti, P. (2006). Do Phonologic and Rapid Automatized Naming Deficits Differentially Affect Dyslexic Children with and without a History of Language Delay? A Study of Italian Dyslexic Children. Cognitive and Behavioral Neurology, 19, 141-149. https://doi.org/10.1097/01.wnn.0000213902.59827.19

Bryant, P. E., Bradley, L., Maclean, M., \& Crossland, J. (1989). Nursery Rhymes, Phonological Skills and Reading. Journal of Child Language, 16, 407-428. https://doi.org/10.1017/S0305000900010485

Caravolas, M. (2005). The Nature and Causes of Dyslexia in Different Languages. In M. J. Snowling, \& C. Hulme (Eds.), The Science of Reading: A Handbook (pp. 336-356). Oxford: Blackwell. https://doi.org/10.1002/9780470757642.ch18

Chitiri, F., \& Porpodas, C. (2003). Phonological Awareness and Its Relations to Learning of Reading and Spelling as Well as to Linguistic Ability and Comprehension of Greek. Patras, Greece: Laboratory of Cognitive Analysis of Learning, Language and Dyslexia. University of Patras [In Greek].

Davis, C. J., Gayán, J., Knopik, V. S., Smith, S. D., Cardon, L. R., Pennington, B. F., Olson, R. K., \& DeFries, J. C. (2001). Etiology of Reading Difficulties and Rapid Naming: The Colorado Twin Study of Reading Disability. Behavior Genetics, 31, 625-635. https://doi.org/10.1023/A:1013305730430 
Denckla, M. B., \& Rudel, R. (1976). Rapid “Automatized” Naming (RAN): Dyslexia Differentiated from Other Learning Disabilities. Neuropsychologia, 14, 471-479. https://doi.org/10.1016/0028-3932(76)90075-0

Diamanti, V., Goulandris, N., Stuart, M., Campbell, R., \& Protopapas, A. (2018). Tracking the Effects of Dyslexia in Reading and Spelling Development: A Longitudinal Study of Greek Readers. Dyslexia, 24, 170-189. https://doi.org/10.1002/dys.1578

Fawcett, A., \& Nicolson, R. (1994). Naming Speed in Children with Dyslexia. Journal of Learning Disabilities, 27, 641-646. https://doi.org/10.1177/002221949402701004

Fischer, B., \& Weber, H. (1990). Saccadic Reaction Times of Dyslexic and Age-Matched Normal Subjects. Perception, 19, 805-818. https://doi.org/10.1068\%2Fp190805

Frederickson, N., Frith, U., \& Reason, R. (1997). Phonological Assessment Battery $(P h A B)$. Windsor: NFER-Nelson.

Georgiou, G. K., Parrila, R., Kirby, J., \& Stephenson, K. (2008). Rapid Naming Components and Their Relationship with Phonological Awareness, Orthographic Knowledge, Speed of Processing, and Different Reading Outcomes. Scientific Studies of Reading, 12, 325-350. https://doi.org/10.1080/10888430802378518

Gharaibeh, M., Sartawi, A. A., Dodeen, H., \& Alzyoudi, M. (2019). Effects of Rapid Automatized Naming and Phonological Awareness Deficits on the Reading Ability of Arabic-Speaking Elementary Students. Applied Neuropsychology: Child. https://doi.org/10.1080/21622965.2019.1585247

Heikkilä, R., Närhi, V., Aro, M., \& Ahonen, T. (2009). Rapid Automatized Naming and Learning Disabilities: Does RAN Have a Specific Connection to Reading or Not? Child Neuropsychology, 15, 343-358. https://doi.org/10.1080/09297040802537653

Jensen, A. R. (1965). Scoring the Stroop Test 1. Acta Psycologica, 24, 398-408. https://psycnet.apa.org/doi/10.1016/0001-6918(65)90024-7

Jones, M. W., Snowling, M. J., \& Moll, K. (2016). What Automaticit Deficit? Activation of Lexical Information by Readers with Dyslexia in a Rapid Automatized Naming Stroop-Switch Task. Journal of Experimental Psychology: Learning, Memory and Cognition, 42, 465-474. https://doi.org/10.1037/xlm0000186

Kane, M. J., \& Engle, R. W. (2003). Working-Memory Capacity and the Control of Attention: The Contributions of Goal Neglect, Response Competition, and Task Set to Stroop Interference. Journal of Experimental Psychology and Genetics, 132, 47-70. https://doi.org/10.1037/0096-3445.132.1.47

Landerl, K. H., Freudenthaler, H., Heene M., De Jong, P. F., Desrochers, A., Manolitsis, G., Parrila, R., \& Georgiou, G. (2019). Phonological Awareness and Rapid Automatized Naming as Longitudinal Predictors of Reading in Five Alphabetic Orthographies with Varying Degrees of Consistency, Scientific Studies of Reading, 23, 220-234. https://doi.org/10.1080/10888438.2018.1510936

Lervåg, A., Bråten, I., \& Hulme, C. (2009). The Cognitive and Linguistic Foundations of Early Reading Development: A Norwegian Latent Variable Longitudinal Study. Developmental Psychology, 45, 764-781. https://doi.org/10.1037/a0014132

Logan, G. D. (1997). Automaticity and Reading: Perspectives from the Instance Theory of Automatization. Reading and Writing Quarterly, 13, 123-146. https://doi.org/10.1080/1057356970130203

Lovegrove, W. J., Garzia, R. P., \& Nicholson, S. B. (1990). Experimental Evidence of a Transient System Deficit in Specific Reading Disability. Journal of the American Optometric Association, 61, 137-146.

Lyon, R. G., Shaywitz, S. E., \& Shaywitz, B. A. (2003). Defining Dyslexia, Comorbidity, 
Teachers Knowledge of Language and Reading. Annals of Dyslexia, 53, 1-14. https://doi.org/10.1007/s11881-003-0001-9

Manis, F. R., Seidenberg, M. S., \& Doi, L. M. (1999). See Dick RAN: Rapid Naming and the Longitudinal Prediction of Reading Subskills in First and Second Graders. Scientific Studies of Reading, 3, 129-157.

https://psycnet.apa.org/doi/10.1207/s1532799xssr0302 3 https://doi.org/10.1207/s1532799xssr0302 3

McBride-Chang, C., \& Manis, F. R. (1996). Structural Invariance in the Associations of Naming Speed, Phonological Awareness, and Verbal Reasoning in Good and Poor Readers: A Test of the Double Deficit Hypothesis. Reading and Writing: An Interdisciplinary Journal, 8, 323-339. https://doi.org/10.1007/BF00395112

Melby Lervåg, M., Lyster, C. A., \& Hulme, C. (2012) Phonological Skills and Their Role in Learning to Read: A Meta-Analytic Review. Psychological Bulletin, 138, 322-352. https://doi.org/10.1037/a0026744

Meyer, M. S., Wood, F. B., Hart, L. A., \& Felton, H. (1998). Selective Predictive Value of Rapid Automatized Naming in Poor Readers. Journal of Learning Disabilities, 31, 106-117. https://doi.org/10.1177/002221949803100201

Misra, M., Katzir, T., Wolf, M., \& Poldrack, R. A. (2004). Neural Systems for Rapid Automatized Naming in Skilled Readers. Scientific Studies of Reading, 8, 241-256.

https://psycnet.apa.org/doi/10.1207/s1532799xssr0803 4

https://doi.org/10.1207/s1532799xssr0803 4

Moll, K., Fussenegger, B., Willburger, E., \& Landerl, K. (2009). RAN Is Not a Measure of Orthographic Processing: Evidence from the Asymmetric German Orthography. Scientific Studies of Reading, 13, 1-25.

https://psycnet.apa.org/doi/10.1080/10888430802631684

https://doi.org/10.1080/10888430802631684

Nicolson, R. I., \& Fawcett, A. J. (1994). Reaction Times and Dyslexia. The Quarterly Journal of Experimental Psychology A: Human Experimental Psychology, 47A, 29-48. https://doi.org/10.1080/14640749408401142

Papadopoulos, T. C., Georgiou, G. K., \& Kendeou, P. (2009). Investigating the Double-Deficit Hypothesis in Greek: Findings from a Longitudinal Study. Journal of Learning Disabilities, 42, 528-547. https://doi.org/10.1177/0022219409338745

Papoulia-Tzelepi, P. (1997). Analysis of Phonological Awareness in the Preschool Children. Glossa, 41, 20-41 [In Greek].

Porpodas, C. (1999). Patterns of Phonological and Memory Processing in Beginning Readers and Spellers of Greek. Journal of Learning Disabilities, 32, 404-416.

https://doi.org/10.1177\%2F002221949903200506

Protopapas, A., Archonti, A., \& Skaloumbakas, C. (2007). Reading Ability Is Negatively Related to Stroop Interference. Cognitive Psychology, 54, 251-282. https://doi.org/10.1016/j.cogpsych.2006.07.003

Savage, R., Pillay, V., \& Melidona, S. (2007). Deconstructing Rapid Automatized Naming: Component Processes and the Prediction of Reading Difficulties. Learning and Individual Differences, 17, 129-146. https://psycnet.apa.org/doi/10.1016/j.lindif.2007.04.001 https://doi.org/10.1016/j.lindif.2007.04.001

Scarpina, F., \& Tagini, S. (2017). The Stroop Color and Word Test. Frontiers in Psychology, 8, 557. https://doi.org/10.3389/fpsyg.2017.00557

Snowling, M. J. (2000). Dyslexia (2nd ed.). Oxford: Blackwell.

Spring, C., \& Davis, J. M. (1988). Relations of Digit Naming Speed with Three Compo- 
nents of Reading. Applied Psycholinguistics, 9, 315-334.

https://psycnet.apa.org/doi/10.1017/S0142716400008031

https://doi.org/10.1017/S0142716400008031

Stanovich, K. E. (1988). Explaining the Difference between the Dyslexic and the Garden Variety Poor Reader: The Phonological-Core Variable-Difference Model. Journal of Learning Disabilities, 21, 590-604. https://doi.org/10.1177\%2F002221948802101003

Stroop, J. R. (1935). Studies of Interference in Serial Verbal Reactions. Journal of Experimental Psychology, 18, 643-662. https://doi.org/10.1037/h0054651

Swanson, H. L., Necoechea, D., Trainin, G., \& Hammill, D. D. (2003). Rapid Naming, Phonological Awareness and Reading: A Meta-Analysis of the Correlation Evidence. Review of Educational Research, 73, 407-440. https://doi.org/10.3102/00346543073004407

Tafa, E. (1997). Reading and Writing at the Preschool Education. Athens: Ellinika Grammata [In Greek].

Vaessen, A., Bertrand, D., Toth, D., Csepe, V., Faisca, L., Bloomert, L., \& Reis, A. (2010). Cognitive Development of Fluent Word Reading Does Not Qualitatively Differ between Transparent and Opaque Orthographies. Journal of Educational Psychology, 102, 827-842. https://doi.org/10.1037/a0019465

Van den Bos, K. P., Zijlstra, B. J., \& Spelberg, H. C. (2002). Life-Span Data on Continuous-Naming Speeds of Numbers, Letters, Colors, and Pictured Objects, and Word-Reading Speed. Scientific Studies of Reading, 6, 25-49.

https://psycnet.apa.org/doi/10.1207/S1532799XSSR0601 02 https://doi.org/10.1207/S1532799XSSR0601 02

Waber, D. P., Wolff, P. H., Forbes, P. W., \& Weiler, M. D. (2000). Rapid Automatized Naming in Children Referred for Evaluation of Heterogeneous Learning Problems: How Specific Are Naming Speed Deficits to Reading Disability? Child Neuropsychology, 6, 251-261. https://psycnet.apa.org/doi/10.1076/chin.6.4.251.3137 https://doi.org/10.1076/chin.6.4.251.3137

Wimmer, H. (1993). Characteristics of Developmental Dyslexia in a Regular Writing System. Applied Psycholinguistics, 14, 1-33. https://doi.org/10.1017/S0142716400010122

Wimmer, H., \& Mayringer, H. (2002). Dysfluent Reading in the Absence of Spelling Difficulties: A Specific Disability in Regular Orthographies. Journal of Educational Psychology, 94, 272-277. https://doi.org/10.1037/0022-0663.94.2.272

Wolf, M., \& Bowers, P. G. (1999). The Double-Deficit Hypothesis for the Developmental Dyslexias. Journal of Educational Psychology, 91, 415-438.

https://psycnet.apa.org/doi/10.1037/0022-0663.91.3.415

https://doi.org/10.1037/0022-0663.91.3.415

Wolf, M., O’Rourke, A. C., Gidney, C., Lovett, M., Cirino, P., \& Morris, R. (2002). The Second Deficit: An Investigation of the Independence of Phonological and Naming-Speed Deficits in Developmental Dyslexia. Reading and Writing: An Interdisciplinary Journal, 15, 43-72. https://doi.org/10.1023/A:1013816320290

Yang, Y., \& Pae, S. (2018). Korean First Graders' Word Decoding Skills, Phonological Awareness, Rapid Automatized Naming, and Letter Knowledge with/without Developmental Dyslexia. Phonetics and Speech Sciences, 10, 51-60.

https://doi.org/10.13064/ksss.2018.10.2.051

Zeliou, G., Sini, T., Anagnostopoulou, D. \& Lazaratou, E. (2008). Construction and Standardization of a Reading Test for Children Aged 7 to 8 Years Old. Themata Eidikis Agogis, 41, 16-27 [In Greek]. 
Ziegler, J. C., Bertrand, D., Toth, D., Csipe, V., Reis, A., Favsca, L. et al (2011). Orthographic Depth and Its Impact on Universal Predictors of Reading: A Cross-Language Investigation. Psychological Science, 21, 551-559.

https://doi.org/10.1177/0956797610363406 


\section{Appendix}

Table A1. (a) provides the scoring system of the reading task (accuracy, reading time and reading comprehension). The task included 5 assessment levels per category. (b) presents the composite scores on reading based on reading speed and the number of errors.

(a)

\begin{tabular}{cccccc}
\hline Time & Scores & Reading errors & Scores & Read. Compr. & Scores \\
\hline $0-66 "$ & Very Fast 5 & $0-3$ & Minimum 5 & $21-24$ & Very good 5 \\
$67 "-82^{\prime \prime}$ & Fast 4 & $4-5$ & Very Few 4 & $18.5-20.5$ & Good 4 \\
$83^{\prime \prime}-95^{\prime \prime}$ & Normal 3 & $6-8$ & Few 3 & $16.5-18.0$ & Moderate 3 \\
$96 "-120 "$ & Slow 2 & $9-14$ & Enough 2 & $13.5-16.0$ & Low 3 \\
$121 "+$ & Very Slow 1 & $15+$ & Many 1 & $0.0-13.0$ & Very low 2 \\
\hline
\end{tabular}

(b)

\begin{tabular}{cccccc}
\hline $\begin{array}{c}\text { Reading errors/time } \\
\text { (per sec.) }\end{array}$ & $(\mathbf{1 5 + )} \mathbf{1}$ & $\mathbf{( 9 - 1 4 ) \mathbf { 2 }}$ & $\mathbf{( 6 - 8 )} \mathbf{3}$ & $\mathbf{( 4 - 5 )} \mathbf{4}$ & $\mathbf{( 0 - 3 ) 5}$ \\
\hline$\left(121^{\prime \prime}+\right) 1$ & 2 & 3 & 4 & 5 & 6 \\
$\left(96^{\prime \prime}-120^{\prime \prime}\right) 2$ & 3 & 4 & 5 & 6 & 7 \\
$\left(83^{\prime \prime}-95^{\prime \prime}\right) 3$ & 4 & 5 & 6 & 7 & 8 \\
$\left(67^{\prime \prime}-82^{\prime \prime}\right) 4$ & 5 & 6 & 7 & 8 & 9 \\
$($ Up to 66") 5 & 6 & 7 & 8 & 9 & 10 \\
\hline
\end{tabular}

